\title{
MOLECULAR INTERACTION ANALYSIS OF POLAR LIQUIDS ACETONITRILE, ACEOPHENONE, 2-PROPANOL IN NON-POLAR BENZENE SOLVENT TREATED WITH MICROWAVE FREQUENCY
}

\author{
D. K. Gupta ${ }^{1}$, Uthaya Kumar. B ${ }^{2}$, G. Meenakshi ${ }^{3}$ \\ ${ }^{1,3}$ Associate Professor, ${ }^{2}$ Research Scholar, Department of Physics, Kanchi Mamunivar Centre for Post Graduate Studies, Lawspet, \\ Puducherry, India
}

\begin{abstract}
The study of dielectric liquid behaviour under different exposure is one of the most fascinating frontiers in solid state physics. It has undoubtedly render considerable service to every physicist doing research in this field. The increasing desire to understand the molecular interactions have led to conduct the present study, which deals with a certain group of polar compounds such as ( $i)$ Acetonitrile (AN), (ii) Acetophenone (AP) and (iii) 2-Propanol (2-P) with a non-polar compound benzene. The dielectric behaviour of individual compound, binary mixtures and their ratios have been studied at microwave frequency of $21.68 \mathrm{GHz}$ in non-polar solvent (benzene) at constant temperature $300 \mathrm{~K}$. Different dielectric parameters like dielectric constant $\varepsilon^{\prime}$ and dielectric loss $\varepsilon "$ at microwave frequency, static dielectric constant $\varepsilon_{s}$ at $1 \mathrm{KHz}$ frequency, dielectric constant $\varepsilon_{\infty}$ at optical frequency have been determined. Using these dielectric data, dipole moment $\mu$, various relaxation time viz (i) molecular relaxation time $\tau_{(1)}$ (ii) overall relaxation time of a molecule $\tau_{(2)}$ and (iii) average relaxation time $\tau_{(v)}$, distribution parameter $(\alpha)$ of individual compound, binary mixtures and their ratios in dilute solutions of benzene also have been determined experimentally. Weight fraction method is used for changing the concentration of solute in solvent. The observed results are discussed on the basis of various types if relaxation processes, which change with the size, shape and type of interaction.
\end{abstract}

Key Words: Molecular Iteraction, Relaxation Time and Dielectric Constant

\section{INTRODUCTION}

The dielectric studies are used for knowing the nature and stength of intermolecular interactions in pure liquids and their mixtures. Particularly the microwave dielectric studies give information about the alignment of neighbouring molecules as well as the types of assoviation in the systems. This study also yields information regarding the sturcture and the nature of molecular orientation process.The molecular relaxation behaviour shaows characteristic interaction and structural features in liquids. The present work consists of dielectric relaxation and absorption studies of some polar liquids and their mixtures in non-polar solvent benzene at microwave frequency (K-Band) $21.68 \mathrm{GHz}$. Different dielectric parameters such as dielectric constant, relaxation time, distribution parameter and dipole moment are calculated using the experimentally observed values. It is observed that relaxation behaviour depends upon the concentration of individual polar liquids and their ratio of binary mixtures in benzene.

\section{THEORETICAL CONSIDERATION}

The dielectric constant $\left(\varepsilon^{\prime}\right)$ and dielectric loss ( $\left.\varepsilon^{\prime \prime}\right)$ of samples are obtained by using the following equation of Poley's method ${ }^{1}$.

$\varepsilon^{\prime}=\left[\lambda_{0} / \lambda_{c}\right]^{2}+\left[\lambda_{0} / \lambda_{d}\right]^{2}\left[1-\left\{\alpha_{d} \lambda_{d} / 2 \Pi\right\}^{2}\right] \varepsilon^{\prime \prime}=(1 / \Pi)\left[\lambda_{0} / \lambda_{c}\right]^{2} \alpha_{d}$ $\lambda_{\mathbf{d}}$

Where,

$$
\alpha_{d}=\left[2 \lambda_{g} / \lambda_{d}^{2}\right]\left[d \rho_{\text {mean }} / d n\right]
$$

is the attenuation constant in the dielectric, $\lambda_{0}$ - Free space wavelength of microwave $\lambda_{c}-$ Cut off wavelength in the wave guide $\lambda_{d}$ - Wavelength of mirowave radiation in dielectric Dielectric constant $\left(\varepsilon_{\infty}\right)$ of the samples at optical frequency are computed with Abbe's refractometer using sodium dline. Static dielectric constant $\left(\varepsilon_{\mathrm{s}}\right)$ of the samples are measured with LCR bridge. The expressions used to compute distribution parameter $(\alpha)$ and various relaxation time are as follows ${ }^{2-8}$ :

$$
\alpha=1-(2 / \Pi) \tan ^{-1}[\mathrm{~A} / \mathrm{B}]
$$

Where, $\mathbf{A}=\mathbf{a}$ " $\left(\mathbf{a}_{0}-\mathbf{a}_{\infty}\right)$

$\left(\mathbf{a}_{0}-\mathbf{a}^{\prime}\right)\left(\mathbf{a}^{\prime}-\mathbf{a}_{\infty}\right)-\mathbf{a}^{, 2}$

$\mathbf{a}^{, 2}$

$\mathrm{a}_{0}, \mathrm{a}^{\prime}, \mathrm{a}$ '” and $\mathrm{a}_{\infty}$ are the slopes obtained by plotting $\varepsilon_{\mathrm{s}}, \varepsilon^{\prime}, \varepsilon^{\prime}$ and $\varepsilon_{\infty}$ versus weight fraction.

$$
\begin{aligned}
& \tau_{(1)}=\left[\mathbf{a} " / \mathbf{w}\left(\mathbf{a}^{\prime}-\mathbf{a}_{\infty}\right)\right] \\
& \tau_{(2)}=\left[\mathbf{a}_{0}-\mathbf{a} / \mathbf{w} \mathbf{a}^{\prime}\right] \\
& \tau_{(\mathbf{3})}=\sqrt{ } \boldsymbol{\tau}_{(\mathbf{1})} \boldsymbol{\tau}_{(2)}
\end{aligned}
$$

The experiment set up used for this study is shown in figure 1.

\section{RESULTS AND DISCUSSION}

The calculated values of relaxation times, distribution parameters $(\alpha)$, dipole moments and Higgasi parameters for the three polar liquids namely acetonitrile (AN), acetophenone(AP), 2-propanol (2-P) and their binary 
mixtures in the ratios $(1: 3),(1: 1)$, and $(3: 1)$ in polar solvent benzene are given in table 1 . From the table it is observed that the increase in the proportion of acetonitrile in the binary mixtures, shows increase in the Higgasi parameter values of $\mathrm{a}_{0}, \mathrm{a}$ ', and $\mathrm{a}$ '. This shows high reactive nature of acetonitrile in the mixture. The reactive nature of acetonitrile is found to be greater than acetophenone. The positive value of $\mathrm{a}_{\infty}$ for acetophenone is due to the increase of refractive index with increase of concentration at optical frequency while for all other systems it is found to be reversed.

The values of dipole moments for individual systems and their binary mixtures for various complexes in benzene are determined by two different methods such as Guggenheim and Higgasi. The dipole moment in both the cases agree with each other and also with the literature values. It confirms the validity of the experimental results obtained. It is also observed that the dipole moments of $\mathrm{AN}+\mathrm{AP}, \mathrm{AN}+2-$ $\mathrm{P}$ and $\mathrm{AP}+2-\mathrm{P}$ in benzene.

The variation of relaxation times viz.. (i) molecular relaxation time $\tau_{(1)}$, (ii) overall relaxation time of a molecule $\tau_{(2)}$ and (iii) average relaxation time $\tau_{(v)}$ of $\mathrm{AN}+\mathrm{AP}, \mathrm{AN}+2 \mathrm{P}$ and $\mathrm{AP}+2-\mathrm{P}$ in benzene versus different ratio of mixtures $(0: 1,1: 3,1: 1,3: 1$ and 1:0) are plotted in figures 2 to 4 . In the case of $\mathrm{AN}+\mathrm{AP}$ and $\mathrm{AN}+2-\mathrm{P}$ in benzene, the (1:1) ratio

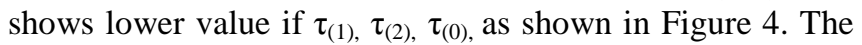
variation of $\tau_{(0)}$ gradually increases with increase of ratios from $0: 1$ to $1: 0$. The rapid increase of $\tau_{(2)}$ with increase of ratios shows the higher contribution of acetophenone in 2propanol. It reveals the rigid nature of acetyl group present in the acetophenone compare with alcoholic group in 2propanol.

The non-linear variation of relaxation time of different ratios of one of the system is interpreted as possible solute-solute molecular association in the binary mixtures. In the present case the non-linear variation of the relaxation time with the change of proportion of acetonitrile in the binary mixture shows the presence of solute-solute molecular association. The value of relaxation time is maximum at 3:1 ratio of $\mathrm{AN}+\mathrm{AP}$ and $\mathrm{AN}+2-\mathrm{P}$ binary mixtures in benzene. This indicates that the molecular association is maximum at 3:1 ratio.

In the case of acetonitrile in (1:1) ratio, the fall of relaxation time with the addition of acetophenone indicates the presence of solute-solvent association in addition to the solute-solute association. The molecular association arises because of the interaction of negative fractional charge at the site of nitrogen atom acetonitrile $\left(\mathrm{CH}_{3} \mathrm{CN}\right)$ molecule and a fraction of positive charge on the carbon atom of acetophenone ${ }^{9}$. In general, the observed result, show the high associative nature of acetonitrile compared to 2propanol and acetophenone. The variation of distribution parameter of individual systems and other complexes confirms the presence of more than one relaxation mechanism. It also confirms the high associative nature of acetonitrile compare to 2-propanol and acetophenone.

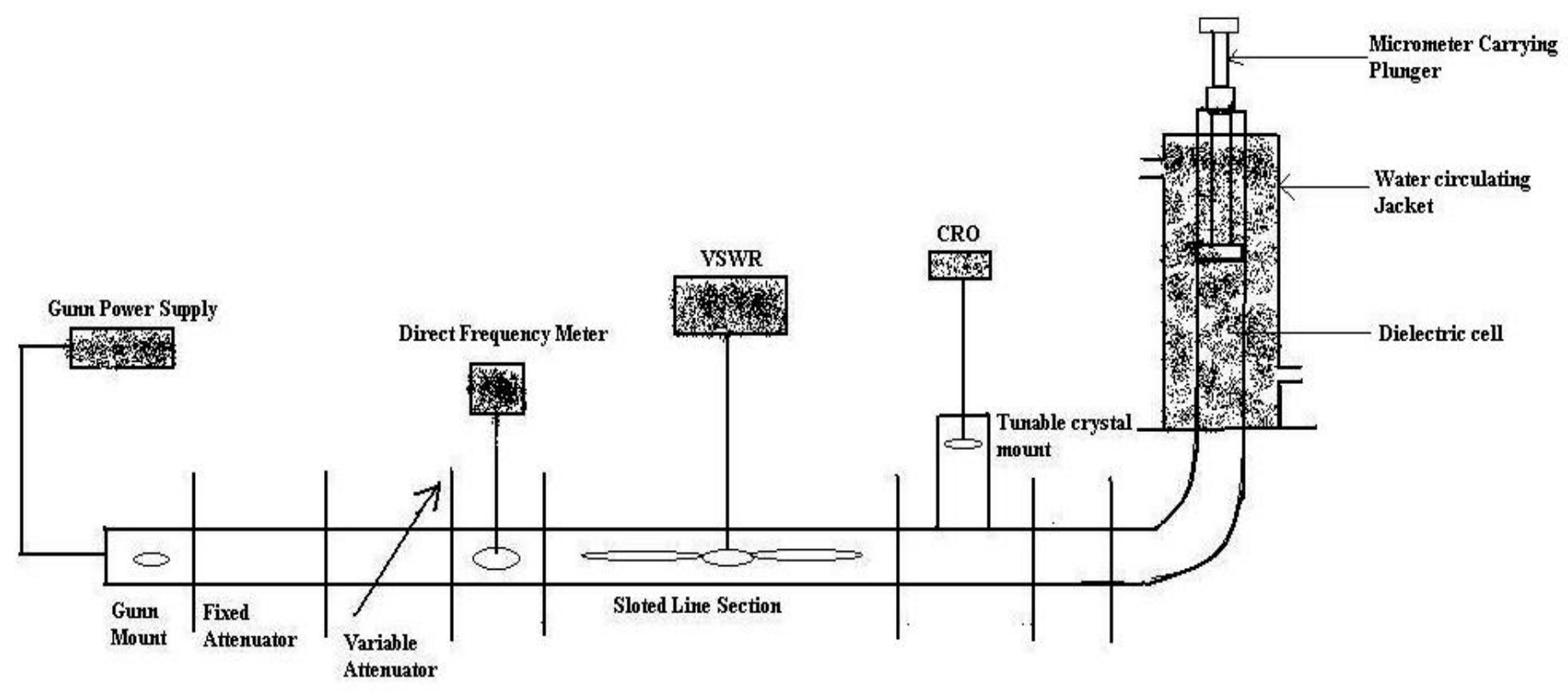

Figure 1: Schematic diagram of K-Band Microwave bench 
Table 1: Calculated values of relaxation times, distribution parameters, dipole moments and Higassi parameters for various systems in Benzene at $300 \mathrm{~K}$

\begin{tabular}{|c|c|c|c|c|c|c|c|c|c|c|}
\hline \multirow[t]{2}{*}{ Systems } & \multicolumn{3}{|c|}{ Relaxation Time(Ps) } & & \multicolumn{2}{|c|}{$\begin{array}{c}\text { Dipole } \\
\text { Moments }\end{array}$} & \multicolumn{4}{|c|}{ Higassi Parameters } \\
\hline & $\tau_{(1)}$ & $\tau_{(2)}$ & $\tau_{(0)}$ & $\alpha$ & $\boldsymbol{\mu}_{(\mathrm{g})}$ & $\boldsymbol{\mu}_{(\mathrm{h})}$ & $\mathbf{a}_{0}$ & $\mathbf{a}^{\prime}$ & a"’ & $\mathbf{a}_{\infty}$ \\
\hline Acectonitrile(AN) & 2.8359 & 29.1615 & 8.2217 & .9997 & 3.9145 & 3.9095 & 39.7250 & 17.3800 & 6.8838 & -0.4450 \\
\hline Acetophenone(AP) & 1.7609 & 27.1659 & 7.1659 & .8408 & 3.0219 & 3.0205 & 8.3050 & 4.3088 & 1.0063 & 0.1125 \\
\hline 2-Propanol (2-P) & 1.7813 & 6.4383 & 3.3865 & .3034 & 1.6625 & 1.6604 & 4.5780 & .7100 & 0.9900 & -0.3712 \\
\hline $\mathbf{A N}+\mathbf{A} \mathbf{P}(\mathbf{1}: 3)$ & 2.3914 & 19.5225 & 6.8 & .5703 & 3.6327 & 3.6321 & 14.1600 & 7.5800 & 2.4 & -0.0200 \\
\hline$A N+A P(1: 1)$ & 2.2956 & 7.7235 & 4.2107 & .3228 & 3.4963 & 3.4523 & 15.7920 & 11.8444 & 3.7532 & -0.1613 \\
\hline $\mathbf{A N}+\mathbf{A P}(3: 1)$ & 2.7556 & 24.0989 & 8.1490 & .5830 & 4.2648 & 4.2593 & 31.8688 & 14.1100 & 5.4113 & -0.3100 \\
\hline$A N+2-P(1: 3)$ & 2.4049 & 18.6484 & 6.6968 & .5595 & 2.6995 & 2.6565 & 13.3688 & 7.1215 & 2.4600 & -0.3900 \\
\hline & 2.3058 & & & 3787 & 2.6854 & & & & & 75 \\
\hline $\mathrm{AN}+2-\mathrm{P}($ & 2.7505 & 23.1195 & 7.9743 & .5784 & 3.6914 & 3.6491 & 30.9300 & 13.9600 & 5.3900 & -0.4300 \\
\hline$A P+2-P(1: 3)$ & 1.7688 & 12.2387 & 4.6527 & .5020 & 2.0175 & 2.0025 & 5.5100 & 3.8600 & 0.9900 & -0.2500 \\
\hline$A P+2-P(1: 1)$ & 1.7733 & 17.8252 & 5.6222 & .5998 & 2.3472 & 2.3412 & 6.4415 & 4.0126 & 1.0 & -0.1200 \\
\hline $\mathbf{A P}+2-\mathbf{P}(3: 1)$ & 1.7632 & 23.5410 & 6.4426 & 6573 & 2.7012 & 2.6818 & 7.3700 & 4.1600 & 1.0013 & -0.0100 \\
\hline
\end{tabular}

$\alpha$ - Distribution Parameter,(AN)- Acectonitrile, (AP)- Acetophenone, (2-P)- 2-Propanol

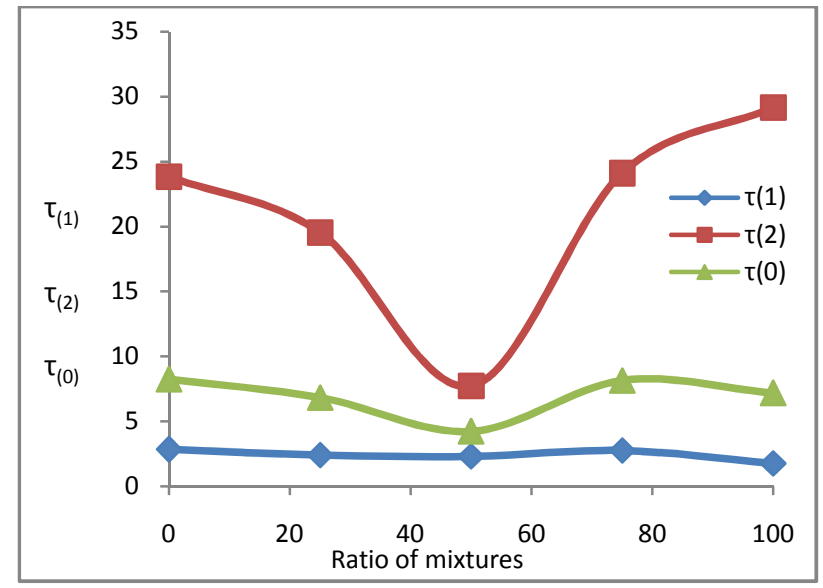

Figure 2: Variation of relaxation times with ratio of mixtures $(\mathrm{AN}+\mathrm{AP})$ in Benzene

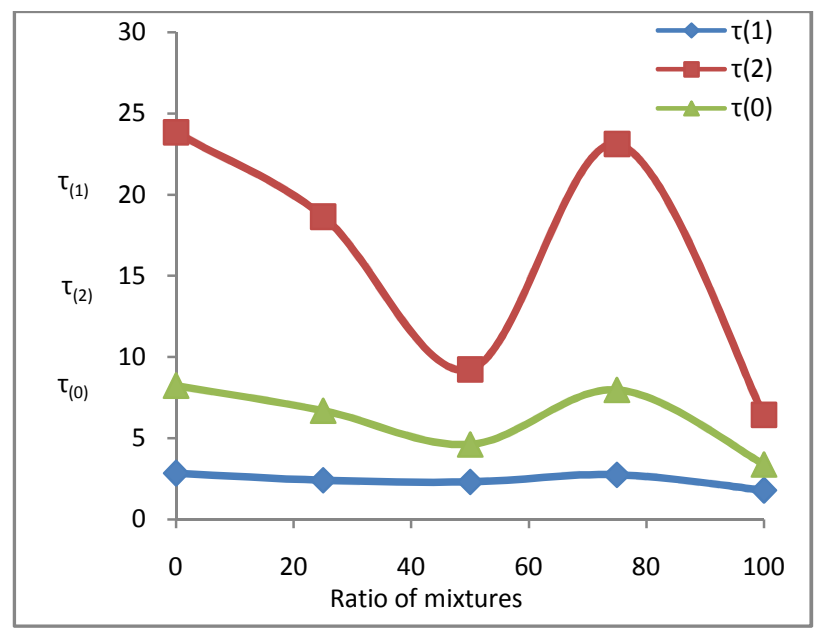

Figure 3: Variation of relaxation times with ratio of mixtures $(\mathrm{AN}+2-\mathrm{P})$ in Benzene

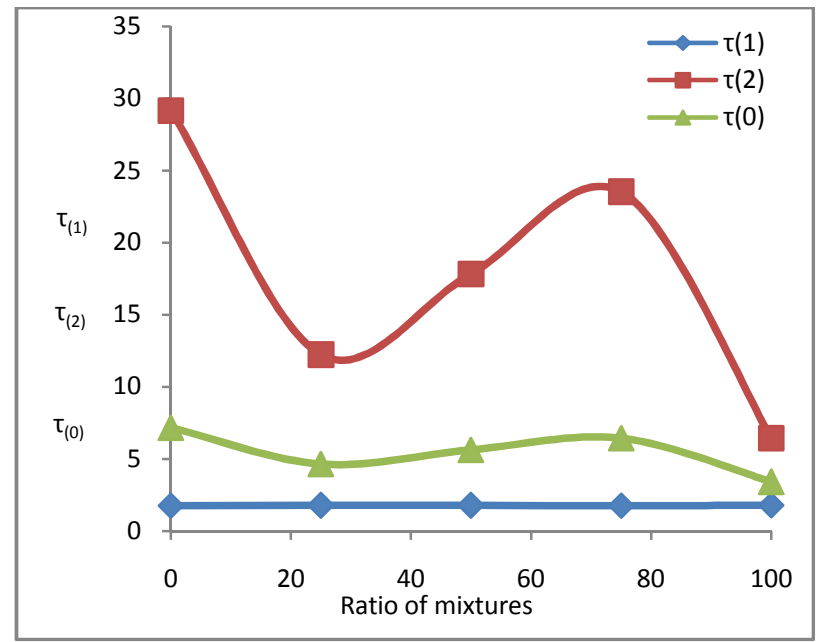

Figure 4: Variation of relaxation times with ratio of mixtures $(\mathrm{AP}+2-\mathrm{P})$ in Benzene

\section{CONCLUSION}

In this paper the relaxation mechanism of some individual polar component and various ratios of their binary mixtures in non-polar solvent benzene is suitably interpreted on the basis of short range interactions such as solute and solutesolvent molecular interactions, arise when the molecules comes closure to each other at microwave frequency. The strong associative nature of polar liquids may be useful in partial fulfillment of the need for using these dielectric liquids for commercial purpose.

\section{REFERENCES}

[1]. Poley, J.P.H., Appl.Scient. Res., 34, 337(1995)

[2]. Higasi.R, and Symth.C.P., J.Am.Chem.Soc., 85, 4759 (1960)

[3]. Kazuo Chitoku and Keniti Highasi,Bulletin Chem.Soc., Japan,39,2160 (1966)

[4]. Kazuo Chitoku and Keniti Highasi,Bulletin Chem.Soc., Japan,36,1064 (1963) 
[5]. Kazuo Chitoku and Keniti Highasi,Bulletin Chem.Soc., Japan,39,2160 (1971)

[6]. S.N. Helambe, M.P. Lokhande, A.C. Kumbharkhane and S.C. Mehrotra, Pramana-J. Phy, 1995, 45(1),19

[7]. S.M. Puranik, A.C. Kumbharkhane and S.C. Mehrotra, J. Chem. Soc. Faraday Trans., 1991, 1569, 87

[8]. V.P. Pawar and S.C. Mehrotra, J. Sol. Chem., 2002, 31(7),.559-576.

[9]. R.H. Cole, J.G. Berbarian, S. Mashimo, G. Chryssikos, A. Burns and E. Tombari, J. Appl. Phys., 1989, 66,793.

[10]. C.E. Shannon, Proc. IRE, 1949, 37,10.

[11]. H.A. Samulan, Proc. IRE, 1951, 39, 175

[12]. P. Debye, Polar molecules, Chemical Catalog, New York, 1929.

[13]. P.R. Bevington, Data reduction and error analysis for the physical sciences, Mc-Graw Hill, NewYork, 1969

[14]. H. Frolhich, Theory of dielectrics, Oxford University Press, London, 1949

[15]. R.C. Weast, Handbook of Chemistry and Physics, 64th ed. CRC Press Boca Raton, Florida, 1983

[16]. A.C. Kumbharkhane, S.M. Puranik and S.C. Mehrotra, J. Sol. Chem., 1993, 22, 219.

[17]. A.G. Bruggeman, Ann. Phys. Leipzig., 1935, 5, 636.

[18]. S.M. Puranik, A.C. Kumbharkhane and S.C. Mehrotra, J. Chem. Soc. Faraday Trans., 1991, 87,1569

[19]. S.N. Helambe, M.P. Lokhande, A.C. Kumbharkhane and S.C. Mehrotra, Pramana-J. Phy., 1995, 45(1), 19.

[20]. S.M. Puranik, A.C. Kumbharkhane and S.C. Mehrotra, J. Chem. Soc. Faraday Trans., 1991, 1569, 87

[21]. V.P. Pawar and S.C. Mehrotra, J. Sol. Chem., 2002, 31(7),.559-576.

[22]. R.H. Cole, J.G. Berbarian, S. Mashimo, G. Chryssikos, A. Burns and E. Tombari, J. Appl. Phys., 1989, 66,793. 